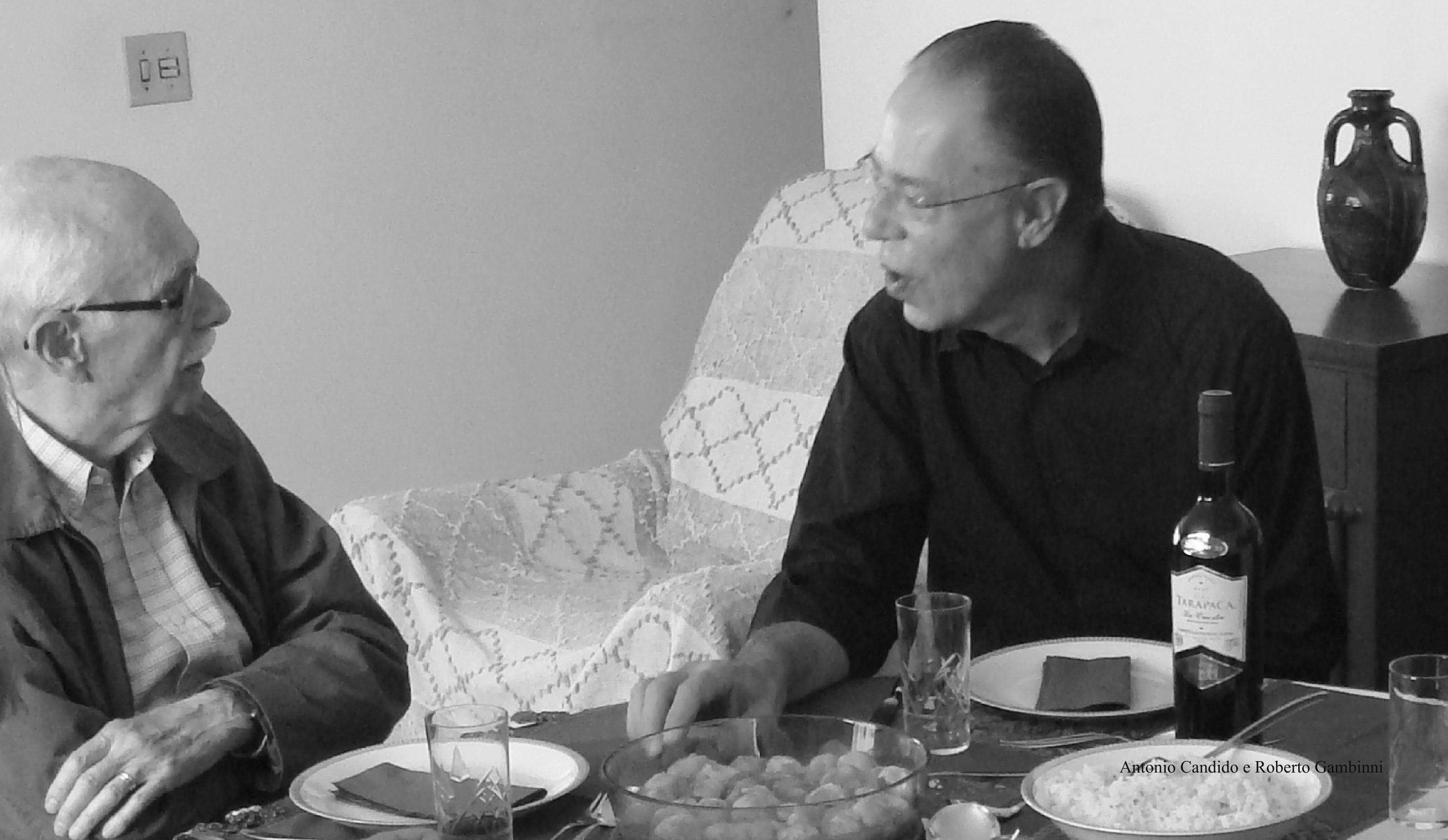



Pocos lis-tu-GG.

alla Dolanes, ru: cordo rella veedis his, $\cos 80$ ance: faluta p'osner. cernives suci cuaty 'allo' aceus. talika Biura. of $x^{2}+y^{2}$ 


\title{
Duas lembranças bem guardadas
}

\author{
Roberto Gambini*
}

Parece pouco, e é, e também um pouco fora dos recortes. Mas estas lembranças são, nas paredes da memória, os quadros que encantam mais, como dizia, com sinais trocados, aquela canção de Belchior. Se os relembro aqui é tão somente porque foi o pedido que recebi e aceitei.

Chegavam juntos ao fim o terceiro ano do Colegial, que era o Clássico, e o ano, de 1962; chegara a hora de tentar a tão falada admissão ao curso superior. "Maria Antonia", naquela época, significava para mim três coisas: a rua propriamente dita, a edificação que ostentava uma colunata tipo grega rente ao meio-fio, e o curso de Ciências Sociais, moderno, dizia-se, arejado, atraente, tão enfaticamente recomendado - à guisa de orientação vocacional, que então inexistia - por dois jovens e belos professores. Um era Paulo Villaça, que nos apresentou as duas literaturas, a portuguesa e a brasileira, estando então por se formar na Escola de Arte Dramática e tendo sido, bem depois, o Bandido da Luz Vermelha no filme de Rogerio Sganzerla. Nos dizia que era fundamental ir ao teatro. A outra, Nilce Cervone, ensinava Filosofia sorrindo e nos aliciava para que aderíssemos à recém-constituída Sociedade Amigos da Cinemateca. Dizia que era fundamental ir ao cinema. E entoavam, ambos: "Direito não, muito melhor ir para a Maria Antonia, que tem o curso mais interessante de São Paulo.”.

* É membro da Sociedade Suíça e da Sociedade Internacional de Psicologia Analítica. Conferencista e ensaísta, formou-se em Ciências Sociais pela USP na década de 1960, fez Mestrado em Ciências Sociais na Universidade de Chicago e após lecionar Ciência Política na Unicamp, nos anos 70, partiu para uma formação em Psicologia Analítica no Instituto Carl Gustav Jung de Zurique. 
Medo de não passar no vestibular não tinha nenhum, sempre levara para casa notas boas, sempre foi gostoso estudar. Narizes torcidos em casa não se fizeram, porém, esperar, e o curso de Direito serviu enfim como moeda de troca, hipoteca mesmo, quitação de supostos débitos filiais para encandecer o desejo e a coragem de enfrentar todo um patriarcado doméstico na esperança de poder tentar a sorte naquela rua, se fosse minha, que me atraía como um pisca-pisca.

Aqueles foram os últimos tempos quando ainda não se falava em cursinhos preparatórios. Ia-se às provas de cara lavada e bem-dormido, levando na ponta da língua tudo o que se havia estudado desde o começo, desde os primeiros anos, e esse tudo bastava. Na Maria Antonia, havia exames orais e também os que demandavam longas e benfeitas redações em páginas duplas de papel almaço timbrado, em caligrafia. Mas tratava-se de apenas um entre os demais, o exame oral de francês, que será doravante devidamente rememorado.

Uma vez estacionado o carro (era um carrão americano passado de pai para filho) em alguma vaga não muito difícil de achar, e tinha que ser grande, e transposta a já referida colunata tipo grega, atravessava o pretendente um vestíbulo estreito e curto ladeado por dois imensos retábulos de madeira escura entalhada, que nada mais eram do que o álbum de formatura dos que naquela hora de nossa entrada já podiam ser nossos examinadores. Causavam reverência, ou piada, as fotos ovaladas perfiladas segundo a ordem alfabética dos nomes dos formandos de antanho, todos com seus capelos e becas lustrosas a lhes cobrirem os ombros. Encabeçando essa turma toda, em fotos maiores, lá estavam os catedráticos, o diretor, reitor e os paraninfos. Nos dias de prova, como o aqui evocado, já se 
atravessava esse corredor polonês amparado ombro a ombro pelo futuro monumental que, espalhado nas paredes, seguramente nos aguardava.

Era então que majestosamente descortinava-se o saguão, que de imponente não tinha nada, muito pelo contrário, mas era a própria cara da Faculdade, era seu pano de boca, sua intimidade, seu átrio e seu fórum, ostentando para atendimento ao público em geral um respeitável balcão também de madeira escura. Quem jamais se esqueceria de Seu Carlos e Dona Floripes, eretos e compenetrados por trás da longa mesa, a desempenhar todo dia com perfeição seus respeitáveis e inespecíficos papéis, que ninguém saberia dizer ao certo quais seriam? Pouco importava. No que eles eram bons mesmo era em prestar-se a guardar ou entregar para algum colega livros e demais empréstimos variados, e informar se alguém procurado já havia chegado. Aquilo ali era uma verdadeira Praça da República, ou do Correio. Eles nos conheciam a todos e eram, aos meus olhos, a contraparte, o casal parental de poucas letras em meio a tantos luminares.

A pintura das paredes era de um bege-acinzentado claro sem a menor graça. As janelas basculantes eram feias, como as que se via nas cozinhas e banheiros das casas da pequena classe média para baixo. Um grande lustre central não havia. A bem dizer não havia nada, nada, além do balcão, que não fosse as seis ou sete portas das salas de aula que haveríamos de ocupar, além da escadaria que levava para a Antropologia, abaixo, e para a Sociologia, no meu caso, acima. Mas era aí, nesse lugar destituído de qualquer beleza, que ocorria o tempo todo a beleza dos encontros.

Naquele fim de ano, talvez por excesso de procura e falta de espaço, até mesmo nesse saguão aberto a todos, realizavam- 
se exames orais, fingindo uns e outros estarmos num recanto protegido de indiscrições, quando a bem dizer o passa-passa era o mesmo de sempre.

E por assim ter sido foi que, ao ouvir chamar meu nome, dirigi-me a uma mesa colocada para esse fim ao lado do degrau ascendente da escada, uma daquelas mesmas mesas retangulares para dois alunos, às quais por anos a fio viríamos a nos sentar no decorrer de nossa tão almejada formação. E a esperar que se apresentasse o candidato, para poder então dar prosseguimento ao exame oral de francês conforme programado, lá estava o mais simpático, o mais acolhedor, elegante e inesquecível examinador que se pudesse haver jamais imaginado.

Levantou-se de pronto, estendeu a mão, sorriu discretamente e indicou a cadeira à sua frente, ficando o candidato de costas para o público. Bastou. Já me sentia de imediato aceito, acolhido e amado pela Maria Antonia inteira.

- O Senhor gosta da língua francesa? - Gosto muito. - Gosta de outras línguas, quais outras teve oportunidade de estudar? - Inglês, como o francês, desde o quinto ano primário, Latim desde a primeira série ginasial, espanhol só no primeiro colegial e italiano no Instituto Cultural Ítalo-Brasileiro, por dois anos. - É capaz de compreender um texto nesses idiomas, consegue se expressar e escrever algumas linhas? - Sim, exceto em latim (risinhos). - O que já leu em francês, algum trecho de literatura? - Alguns excertos dos grandes autores, no livro adotado pela escola: trechos de Balzac, Lamartine, Victor Hugo, Racine, Verlaine, coisas assim. - Lembra-se por acaso de algumas linhas de cor? (Declamo o primeiro verso de Le Lac, de Lamartine: “Ainsi, toujours poussés vers de nouveaux rivages..."). - Poderia agora ler em voz alta estas linhas de Rousseau? (Leio). Está bem. 
Começa por acaso a ter algum interesse em adquirir o hábito de ler em francês? - Sim, estou começando a gostar, uma amiga às vezes empresta revistas como Paris Match e Jours de France e já consigo mais ou menos acompanhar as matérias. Temos em casa um Guia Michelin, que gosto de consultar, e um livro de arte sobre a obra de Manet, de quem gosto muito. - E já leu algum livro até o fim? - Sim, li O Pequeno Príncipe, de SaintExupéry. - E por acaso lembra de alguma passagem, alguma frase que tenha ficado na memória? - Se não me engano, a frase que gravei é "Tu es responsable pour ceux que tu as apprivoisé", ou algo parecido. E esse verbo me deu um certo trabalho para entender. (Traduzindo, "Você é responsável por aqueles que cativou"). - E assim como se lembrou desse trecho, recorda-se de algum outro autor? - Sim, alguns versos daquela tragédia de Racine em que a certa altura Fedra diz que enlanguesce, que arde por Teseu, mas que com Hipólito é que desceria ao Labirinto para encontrar-se, ou perder-se. (E então o examinador, para minha grande comoção, também lembrou-se: "E Phèdre au Labyrinthe avec vous descendue/ Se serai avec vous retrouvée ou perdue."). Naquele preciso instante, senti que o havia de algum modo conquistado. Mas não: eu é que havia, no exame oral de Francês perante um examinador que nem sabia quem era, eu é que havia sido ritualmente conquistado para sempre pelo fascínio da literatura. Literalmente apprivoisé.

De volta a circular pelo saguão, uma colega me pergunta se sabia que havia sido examinado pelo famoso mestre Antonio Candido de Mello e Sousa.

Nunca fui seu aluno, mas pude aos poucos ir conhecendo sua obra e seus ensinamentos. Encantava-me vê-lo andando pela nossa rua lado a lado com a inconfundível Dona Gilda, que aos 
meus olhos juvenis possuía um dos mais belos rostos de senhora que jamais havia visto. Assim como igualmente fascinava ouvir, no Salão Nobre do quarto andar, as arguições da dupla Antonio Candido-Cândido Procópio nas concorridas defesas de tese, especialmente aquelas, renhidas, para obtenção do grau máximo de chefe de cátedra, quando se ficava conhecendo o que era o brilho da inteligência combinada com o rigor crítico e a amorosidade.

Além da calçada sempre cheia, dos encontros estimulantes, da banca de jornais na esquina da rua Dr. Vilanova e do Bar do Zé à noite, na Maria Antonia havia duas ou três livrarias, que passei a frequentar, onde gastava parte da bolsa de estudos que recebera devido às tais boas notas que tirava. Certas lombadas nas estantes atraíam a atenção e o desejo de possuir os livros que encapavam como se fossem sapatos italianos. Pouco a pouco, um a um, fui adquirindo alguns preciosos exemplares, fundadores de uma tão querida biblioteca. Ainda estão quase todos eles aqui à minha volta, e lá se vai mais de meio século. Economia y Sociedad, dois volumes (caro), As Regras do Método Sociológico, O Príncipe, A Função Social da Guerra entre os Tupinambá, Formação Política do Brasil (dois volumes), O Capital, O Contrato Social, Formação da Literatura Brasileira (dois volumes). Algumas revistas, livros com desconto. E alguns achados, porque deviam ser bons e eram baratos, como este, de volta neste instante às minhas mãos: O Observador Literário, também de Antonio Candido, fininho, editado em 1959 pelo Conselho Estadual de Cultura/Comissão de Literatura, São 
Paulo. Esse volume, de breves estudos, inaugura a Coleção Ensaios e as próprias atividades editoriais dessa Comissão.

$\mathrm{Na}$ página de rosto escrevi meu nome com letra miúda e a data, 1963. Só que me enganei, encontrei-o foi na Livraria Parthenon, rua Barão de Itapetininga, 140, $1^{\circ}$ andar. Comprei, porque todos os livros do autor certamente seriam bons, afinal eu o conhecera pessoalmente. E eram. Esse, em especial, me revelava uma forte surpresa. Ao ler o breve ensaio intitulado "Teresina" (p. 94-99; foi publicado pela primeira vez em 1956, no "Suplemento Literário" do jornal O Estado de São Paulo), senti repentinamente dignificada uma jamais imaginada linhagem anímica para minha família de imigrantes italianos.

Desde muito cedo, em geral nas conversas em torno da mesa de jantar, eu ouvia mencionar o nome de Zia Teresina, que morava em Poços de Caldas, usava um toucado e gostava de gatos. Havia visto uma foto sua, com seus "oclinhos", um filhote de gato branco ao colo, sentada numa cadeira posta no jardim da que certamente seria sua casa, antiga, e com um sorriso que me parecia ao mesmo tempo doce e um pouco assustador, porque era bem velhinha e eu nunca a havia visto pessoalmente. Não foi difícil localizar essa pequena fotografia de margem serrilhada, datada de Poços 4-11-44. Estava bem aqui na estante, num velho álbum que herdei. A caligrafia era firme, a tinta, azul, e a dedicatória diz: "Alla Dolores, ricordo della vecchia zia, con 80 anni".

Teresina fora casada com o maestro violoncelista Guido Rocchi, que vinha ser o tio materno de minha avó Dolores. Guardo até hoje um cartão postal, de lindo colorido, que minha mãe enviara de Poços de Caldas a meu pai, quando, grávida deste que aqui rememora, passava uma temporada junto à tia do 
marido, porque ambas se queriam. De um e de outro, na família, sempre ouvi falar algo peculiar dessa estimada Zia Teresina.

Mas ao ler o que sobre ela escreveu Antonio Candido, que com ela conviveu durante os anos em que seu pai atuou como médico nessa estação de águas, dou-me conta da extraordinária pessoa que ela foi, e de como e quanto posso supor que tenha sido - analista junguiano que me tornei - uma personificação, para o jovem e talentoso rapaz, da Anima inspiradora e criativa em sua configuração interior mais ética, culta, sensível e humanista que se possa conceber naquelas lonjuras interioranas. Ou, deixando de lado a compreensão junguiana da importância desse fator na dinâmica interna da psique masculina, gosto de pensar em minha tia-bisavó como um modelo vivo e autêntico daquele cordial socialismo que iluminou o pensamento radical, os valores éticos, a inteireza e a sensibilidade de nosso querido Mestre.

Só não posso entusiasmar-me demais, porque não descendo dela, mas da mãe do marido, a tataravó Enrichetta Del Bono, nascida em Parma, em 1839, e que trabalhou como professora de meninas na aldeia de Fontanellato, ao redor de um antigo casteloforte, nas vizinhanças de Parma. Casou-se ela com Leovigildo Rocchi, com quem teve três filhos, Gemma (minha bisavó), Guido, que se casou com Teresina, e Leovigildo, o violinista. Guido estudou na Regia Scuola di Musica di Parma, onde foi colega de Arturo Toscanini, graças à intervenção obsequiosa do Conde Sanvitale, membro da aristocrática e antiga família proprietária da Rocca di Fontanellato, onde vivia também a família Carini, de Teresina. Seu avô, e depois seu pai, foram administradores dos bens da família nobre. Em 1890, Guido, sua mulher Teresina e o jovem Leovigildo desembarcaram em Santos, músicos que eram da orquestra de uma companhia 
de ópera. E, diga-se de passagem, o que aqui anoto apenas transcrevo do diário que nos deixou nossa tataravó Enrichetta, abundante em letras e lágrimas.

Por outro lado, pois nem tudo é genético, parentescos há tecidos por outros fios. O breve escrito "Teresina", posteriormente bastante ampliado pelo autor e publicado em 1980 pela Paz e Terra (p. 11-80), inspirou-me a escrever, muitos anos depois, "Corações Partidos no Porto de Gênova" (Revista do Instituto de Estudos Avançados da Universidade de São Paulo, n. 57, mai,-ago. 2006, p. 264-296). Eu precisava ter uma ideia do que sentiam, e nada diziam, esses antepassados que partiam e nunca mais voltavam.

O que verdadeiramente me inspirou, como vim a reconhecer muitos anos depois, foi o modo como Antonio Candido, num breve retrato, foi capaz de evocar um tempo crítico e uma criatura fora do comum adentrando sem delongas o terreno quente da subjetividade, do de dentro, do que se pensava e lia, do íntimo da paisagem, do interno da casa, do sombreado da sala, tudo como pano de fundo e palco para uma pessoa inteira, sempre "fremindo de inteligência e generosidade", que é como a resume. "Teresina" não é biografia, mas gravação de movimento, registro de sotaque, repertório de valores e opiniões, presença e parecença de alguém querido que soube viver seu tempo e ocupar seu lugar sem meias-medidas nem meias-verdades. $O$ que em outros textos memorialistas costuma compor exterioridades, neste revela a época e a cena pelo olhar agudo e as atitudes certeiras de uma mulher que sempre agiu e pensou como combatente. E pelo olhar amoroso e profundo de seu amigo mais moço.

Detive-me certa vez a cotejar os dois textos, o breve e o expandido, buscando adivinhar onde o autor sabia haver espaço 
para inserir matéria ausente na primeira versão. O ensaio original principia com alguns dados biográficos básicos, ocupando menos de uma página, e já nos põe em contato direto com a figura de Teresina. $\mathrm{O}$ cotejamento dessa abertura nos dois textos, separados por vinte e quatro anos, creio ser capaz de revelar algo sobre os vários recursos do ofício do escritor, e mais do que isso, o material vivido retido por décadas na memória, que pode, uma vez invocado, respirar de novo nas expansões e detalhamentos que vieram a tornar o segundo escrito tão parecido com uma deliciosa conversa que se prolonga noite adentro sem hora de acabar.

$\mathrm{Na}$ rápida abertura da primeira versão, ficamos sabendo que Teresina, "nascida à sombra do castelo feudal dos condes Sanvitale", foi casada com um violoncelista, com quem veio para o Brasil em 1890. A segunda publicação, que recebeu o título de Teresina e seus Amigos, subdivide-se em três partes: "Crônica Inicial", "O ser e as "convições" e "Os outros". Na primeira, à guisa de prólogo, como numa ópera, o autor parte do lugar de origem, Fontanellato, nome do castelo e da aldeia circundante onde viveram tanto a família dela como um ramo da minha, com pertinentes comentários a respeito da trama tecida pelo convívio entre nobres e o extrato plebeu que a eles se agregava. Seguemse os trechos intitulados "Música e Brasil" e "O Casal Mal Afinado", sendo o leitor passo a passo, conhecendo o terreno, conduzido à apresentação da figura central da narrativa.

$\mathrm{O}$ retrato original, dispensando maiores introduções, principia assim: "Era magra, nem alta nem baixa, cabelos louros que só embranqueceram nos últimos anos, grandes olhos azuis de espantosa mobilidade e penetração...”. No segundo retrato ampliado, como se fosse pintura feita em tela maior, surge uma 
curiosa variante de descrição dos olhos: "Tinha olhos azuis abertos e redondos, exprimindo de maneira incrível os matizes de um espírito trepidante". Na primeira abordagem o olhar penetra; na segunda, revela.

Vem em seguida o registro da aparência de Teresina, havendo mínimos acréscimos e algum qualificativo adicional. O detalhe e o preciosismo da composição do porte dessa mulher que não imitava a nenhuma outra conduzem à lembrança das instruções que Luchino Visconti deve ter dado ao figurinista de sua equipe para criar o estilo de uma das velhas senhoras que habitavam a mansão do Gattopardo, o que aliás já comparece na própria escrita de Tommaso di Lampedusa.

Mas o que me fascinou desde a primeira leitura, e que não resisto agora a comparar com a segunda, foi a recriação da casa onde morava Teresina, que me remetia aos climas criados por Marcel Proust em suas páginas sobre interiores, e que deixou desde então plantada a semente de uma vontade futura, a de um dia poder tirar do baú que havia na casa de meus pais essa matéria que pode voltar a pulsar graças à magia da escrita. Como numa colagem, usando o itálico como contraste, as duas descrições da casa de Poços de Caldas serão sobrepostas e vistas contra a luz, como se escritas em papel de seda, para que se perceba como trabalham juntas, num fuso unificado, a memória, a criação literária e o amor para tecerem seus brocados.

A casa onde morava era, de certo modo, a sua também involuntária obra prima. A casa onde morava tinha também um ar original e raro... Modesta e acachapada, 0 toque de sineta abria a porta de uma estranha penumbra, povoada de mais coisas do que o espaço permitia. Sofás e poufs de cretone estampado, lâmpadas, móveis, quadros, quadros e mais quadros, livros e mais livros. ...cheia de sofás e poufs de cretone estampado, lâmpadas 
pintadas (inclusive uma com as quatro estações), móveis antigos, uma espécie de panóplia de veludo crivada de fotografias e postais, livros e mais livros, embora nunca em proporção ao volume das suas leituras. Ela achava que livro era feito para circular e passava adiante os que comprava ou ganhava, depois de lançar na margem as suas impressões. Mas nunca se desfazia de alguns, sobretudo os de Leopardi, que era a sua maior paixão literária. Ali estava, em ordem revôlta, o reflexo da sua vida, multiplicada nas alfaias. Pastas brasonadas do Castelo, autógrafos dos condes, dedicatórias de artistas, álbuns com vistas da Europa, recordações de camarim e sala de concerto, louças de naufrágio, objetos do sertão, manifestos radicais, jornais e revistas de todas as épocas. De certo modo a casa refletia a sua vida através dos objetos que assinalavam a passagem do tempo: pastas brasonadas da Rocca, autógrafos dos amigos, dedicatórias de artistas, álbuns de postais, recordações de camarim e sala de concerto, objetos do sertão, manifestos radicais, jornais e revistas de todas as épocas. O quintal, longo e estreito, perfumava-se de lírios roxos, ervilhas de cheiro, loureiros e vários temperos de sua refinada culinária emiliana. No quintal havia os temperos da sua culinária emiliana e muitas flores: além das violetas de vário tipo, lírios roxos, ervilhas de cheiro, espirradeiras (ou, como preferia dizer, giaggioli, pois de senteur, lauriers roses). E dela se desprendia sempre um vago cheiro de flor.

Esse mesmo exercício de sobreposição pode igualmente ser feito com os magníficos parágrafos que Antonio Candido escreveu sobre os traços de personalidade de Teresina, seu modo de ser socialista, a maneira como nela os opostos conviviam sem guerra. Não se diga que tenha havido uma evolução, ou mesmo amadurecimento literário, na comparação entre textos; o que se pode imaginar é que ambos, bem costurados, fariam um só, de um estilo furta-cor. Por exemplo, repare-se, ora é dito que ela fuzilava e aveludava os olhos, ora que fuzilava e amansava. Uma forma não supera a outra; a variação revela, pelo 
contrário, os vários prismas de um olhar amoroso: nesse caso, o do autor. E não posso deixar de notar que quando o jovem amigo admira e percebe o extraordinário daquela personalidade, "cheia de inquietude, ardor e bravura", para quem "não havia abismo e nem mesmo frincha entre a concepção e a conduta", ele possivelmente retratava um lado seu ainda na crisálida, que entrevia no rosto de Teresina, seu espelho mágico.

\section{$* * *$}

Vinte e cinco anos depois dessa segunda leitura, em que ficava reiterada a primeira forte impressão já gravada em algum lugar de onde brota a escrita, e sem a menor desconfiança de que era essa marca indelével o que me inspirava ao começar a esboçar um ensaio próprio, comecei assim:

Na casa de meu pai havia um cômodo que chamávamos de "escritório. Abria-se para uma pérgola coberta por ramos de videira... sua escrivaninha era imponente... minha mãe, que lá fazia maravilhosas flores de seda... o armário com portas retráteis... o enxoval de minha tia solteira... os brinquedos Estrela... um caixote de madeira... recibos, faturas... cartazes de propaganda... folhetos do Amaro Gambarotta... fotografias da casa Alinari... carteiras modelo $19 . .$. e uma grande coleção de cartões postais cujas mensagens não decifrava... caligrafias antiquadas... Esse caixote de madeira continha o mistério da Itália.

E passo a passo, de umas linhas a outras manuscritas do verso dos cartões postais, fui tentando decifrar o que não era dito nem pelos que partiram, nem pelos que ficaram. O que só produziu engasgos e emoções engolidas.

Melhor fez Zia Teresina. Veio, ficou porque quis, e não deixou uma palavra sem dizer. 